\title{
Menocchio, meunier du Frioul: a star is born
}

\section{Danièle Tosato-Rigo}

\section{(2) OpenEdition}

Journals

Édition électronique

URL : http://journals.openedition.org/edl/2361

DOI : 10.4000/edl.2361

ISSN : 2296-5084

\section{Éditeur}

Université de Lausanne

\section{Édition imprimée}

Date de publication : 15 mars 2020

Pagination : 91-94

ISBN : 978-2-940331-73-4

ISSN : 0014-2026

\section{Référence électronique}

Danièle Tosato-Rigo, « Menocchio, meunier du Frioul: a star is born », Études de lettres [En ligne], 312 | 2020, mis en ligne le 24 mars 2020, consulté le 17 septembre 2020. URL : http://

journals.openedition.org/edl/2361; DOI : https://doi.org/10.4000/edl.2361 


\section{MENOCCHIO, MEUNIER DU FRIOUL: A STAR IS BORN}

C'est l'histoire d'un meunier de la fin du XVI ${ }^{\mathrm{e}}$ siècle, dit Menocchio. Comme sa profession l'indique, Menocchio (de son vrai nom Domenico Scandella) n'appartenait pas aux plus déshérités du village de Monreale, dans le Frioul. Mais pas davantage au monde des lettrés. Or il lisait. Rien de particulièrement original, à vrai dire: la Bible en langue vulgaire, le best-seller médiéval des voyages de Mandeville ou le Décaméron de Boccace. La façon dont le meunier se représentait l'univers, "toute tirée de sa tête», était, elle, beaucoup moins ordinaire:

Au commencement, ce monde n'était rien que de l'eau de mer. Elle fut barattée et elle a caillé comme un fromage. Et de ce fromage sont nés des vers en quantité. Et ces vers sont devenus des hommes dont le plus puissant et le plus savant a été Dieu.

Cette cosmogonie peu conformiste d'une génération spontanée n'ayant pas nécessité l'intervention divine, expliquée aux juges de l'Inquisition interloqués, qui après bien des hésitations envoyèrent Menocchio au bûcher, est au centre d'un petit livre de Carlo Ginzburg (128 p.) traduit en 1980: Le fromage et les vers. Cet ouvrage au retentissement phénoménal est demeuré à ce jour emblématique de la microhistoire.

La biographie intellectuelle du meunier, puisque c'est bien de cela qu'il s'agit, s'inscrit dans une période de remise en question de l'histoire sociale quantitative et structuraliste propagée puis institutionnalisée par le courant des Annales, sous la férule de Fernand Braudel. De l'étude de la sorcellerie à celle de la déchristianisation, même les historiens des mentalités privilégiaient alors les sources sérielles. Le livre de Ginzburg innove à divers titres. Reprenant le thème très en vogue de la culture 
populaire, il se distancie de ses prédécesseurs en s'attelant à reconstruire avec Menocchio le tableau foisonnant des pensées d'un seul individu, "de ses sentiments, de ses rêveries et de ses aspirations». Il ménage une large place aux incertitudes des acteurs/actrices, lot quotidien de celles et ceux qui, à l'inverse de l'historien.ne, ignorent la fin et même tout simplement la suite de l'histoire. L'auteur enfreint par ailleurs le code académique en visant à la fois un large public, dans un texte principal aux allures d'enquête policière, et les spécialistes, auxquels il destine des notes finales très érudites.

C'est autour de fragments arrachés à l'archive judiciaire que Ginzburg construit son propos, par le biais de la méthode qu'il appelle indiciaire ${ }^{1}$. Parallèlement à la reconstitution minutieuse du microcosme mental du meunier, elle recourt à des procédures analogiques. Elles lui permettent de tisser des liens notamment entre la cosmogonie de Menocchio, des légendes d'Asie centrale et les vers d'un mythe indien chantés par les Védas. Tout en dévoilant la porosité entre culture populaire et culture savante, l'anomalie que représente le meunier dans son milieu n'empêche ainsi nullement l'historien de généraliser le propos: les déclarations de l'"hérétique» comporteraient selon lui les traits morphologiques d'une culture paysanne orale, empreinte de matérialisme instinctif "tendanciellement scientifique», dont elles permettraient d'esquisser les contours.

L'historien américain James Amelang se remémore le choc que lui causa la lecture du livre en version anglaise, alors qu'il était encore étudiant:

I cannot recall any other book that had a comparable impact on me. It was, to be sure, partly a question of the skill with which the author told and analyzed a fascinating and sympathetic story. But there was also an element of guidance, the way in which the text made a firm statement as to what history was and could be ${ }^{2}$.

Incontestablement, le personnage de Menocchio fascinait, les problématiques centrales de l'ouvrage - la confrontation entre la culture des subalternes et celle des dominants, les croisements entre culture orale et écrite - tout autant. En repensant narration et enquête historiques, c'était aussi une forme d'"empowerment" que Ginzburg offrait aux historien.ne.s voulant rivaliser avec leurs collègues de sciences sociales:

I. Voir C. Ginzburg, «Signes, traces, pistes».

2. J. Amelang, "[Review of] Carlo Ginzburg, The Cheese and the Worms», p. 31 sq. 
ils/elles pouvaient retourner aux documents d'archives sans risquer de passer pour des positivistes.

Dire que l'ouvrage a été traduit dans plus d'une vingtaine de langues peut donner une idée de son retentissement ${ }^{3}$. Les critiques n'ont pourtant pas manqué: sur ses méthodes, sur le non-conformisme de Menocchio, la culture orale populaire à laquelle il était censé renvoyer. Se demandant "comment définir cette obscure mythologie campagnarde», François Billacois, par exemple, s'insurgeait contre l'explication matérialiste, «car enfin ces ruraux du XVI siècle n'ont ni lu ni pressenti le Manifeste communiste" ${ }^{4}$. Pour Dominick LaCapra, à supposer que les composantes principales mises en relief par Ginzburg consistaient dans le matérialisme, l'égalitarisme, la tolérance et l'utopisme, restait à démontrer en quoi elles caractérisaient la culture paysanne ${ }^{5}$. Autre "diamant obscur», le statut exceptionnel (ou non) du meunier du Frioul, que Ginzburg réglait par la formule devenue célèbre d' «exception normale». L'approche transversale de l'historien ne fut pas épargnée: pour le sociologue Giovanni Busino, c'était comparer l'incomparable. L'édition des actes du procès Menocchio, que Ginzburg ne présentait nulle part dans son livre, suscita une relecture des conceptions du meunier, qu'Andrea Del Col estima plus proches du manichéisme cathare. Ginzburg aurait-il péché par surinterprétation? Jean Boutier et Philippe Boutry n'en absolvent l'historien italien que du bout des lèvres, au terme d'un examen approfondi.

Critiques et débats, en filigrane à une forte demande de révision du «paradigme des Annales» (des tenants de l'Alltagsgeschichte, des féministes, etc.), ont contribué au statut de référence de l'ouvrage qui, en essayant de poser des questions plus larges à partir d'une situation individuelle, a propulsé, outre l'archive judiciaire, l'étude de cas dans l'outillage des historien.ne.s. Au fil d'un vibrant plaidoyer pour une histoire érudite et hautement interprétative, laissant toutefois aux protagonistes étudiés leur part de mystère.

\section{Danièle Tosato-Rigo}

Section d'histoire, Faculté des lettres, Université de Lausanne

3. L'ouvrage a été réédité en anglais en 2013 (avec une préface de Carlo Ginzburg), en français en 2014 (avec une préface de Patrick Boucheron).

4. F. Billacois, "[Compte rendu de] Carlo Ginzburg, Il formaggio e i vermi», p. 101.

5. Voir également les comptes rendus de P. Zambelli, V. Valeri et S. Cohn Jr. 


\section{BIBLIOGRAPHIE}

Amelang, James, "[Review of] Carlo Ginzburg, The Cheese and the Worms», Sixteenth Century Journal, XL/1 (2009), p. 31-34.

Billacois, François, «[Compte rendu de] Carlo Ginzburg, Il formaggio e i vermi", Annales. Économies, Sociétés, Civilisations, XXXVI/1 (1981), p. 98-102.

Boutier, Jean, Boutry, Philippe, "L'invention historiographique. Autour du dossier Menocchio", Enquête, 3 (1996), p. 1-10.

Busıno, Giovanni, "Causalisme, symétrie et réflexivité. Une lecture des travaux de Carlo Ginzburg", in L'acteur et ses raisons, Mélanges en l'honneur de Raymond Boudon, Paris, PUF, 2000, p. 25-42.

Conn Jr., Samuel, "[Review of] Carlo Ginzburg, The Cheese and the Worms", Journal of Interdisciplinary History, 12 (1982), p. 523525.

Del Col, Andrea, Domenico Scandella detto Menocchio. I processi dell'Inquisizione (1583-1599), Pordenone, Biblioteca dell'Immagine, 1990.

Ginzburg, Carlo, Il formaggio e i vermi. Il cosmo di un mugnaio del '500, Turin, Einaudi, 1976; Le fromage et les vers. L'univers d'un meunier du XVIe siècle, trad. Monique Aymard, Paris, Flammarion, 1980 ; The Cheese and the Worms: The Cosmos of a SixteenthCentury Miller, transl. John and Anne Tedeschi, Baltimore, John Hopkins University Press, 1980.

—, "Signes, traces, pistes. Racines d'un paradigme de l'indice», Le Débat, 6 (1980), p. 3-44.

LaCapra, Dominick, "The Cheese and the Worms: the Cosmos of a Twentieth Century Historian", in History and Criticism, Ithaca N.Y., Cornell University Press, 1985, p. 54-58.

Valeri, Valerio, "[Review of] Carlo Ginzburg, The Cheese and the Worms", Journal of Modern History, 54 (1982), p. 139-143.

Zambelli, Paola, "[Review of] Carlo Ginzburg, The Cheese and the Worms", The Historical Journal, 28 (1985), p. 983-999. 